\title{
HEIDEGGER E A PSICANÁLISE: UMA CONVERSA EM SICÍLIA
}

\author{
Heidegger and the psychoanalysis: \\ sicilian conversation
}

Vincenzo di Matteo ${ }^{1}$

\section{Resumo}

Pretendo, neste artigo, analisaralgumas críticas pontuais que Heidegger dirige à psicanálise freudiana, restringindo-me à conversa que manteve com Medard Boss, nas férias sicilianas de abril-maio 1963. Após uma breve contextualização do que o próprio Heidegger chamou de 'conversas sicilianas', procuro identificar os horizontes teóricos dentro dos quais elas se situam, analiso as críticas dirigidas à psicanálise enquanto méto do, terapia e metapsicologia e concluo tecendo algumas considerações quanto à sua validade e limites.

Palavras-chave: Psicanálise; Dasein; Método; Terapia; Metapsicologia.

\section{Abstract}

In this Communication, I intend to analyze some punctual critics that Heidegger have directed to freudian psychoanalysis, limiting the comments to the conversation that he maintained with Medard Boss on his Sicilian vacation in 1963 (april - may). After a brief context of what Heidegger himself called 'sicilian conversations', I try to identify the theorical horizons that surrounds it, also analyzing the critics directed to Psychoanalysis as a method, therapy and metapsychology and at last I intend to weave a few considerations about its validity and limits.

Keywords: Psychoanalysis; Dasein; Method; Therapy; Metapsychology.

1 Docente da Universidade Federal de Pernambuco (UFPE) Universidade Federal de Pernambuco. Av. Acad. Hélio Ramos, s/n Cidade Universitária. CEP: 50740-530 Recife, PE - Brasil - Telefone: (081) 32718296 Fax: (081) 32718298.

E-mail :atteo@npd.com.br"dimatteo@npd.com.br

Revista de Filosofia, Curitiba, v. 17 n.20, p. 185-198, jan./jun. 2005. 


\section{Heidegger e Medard Boss}

O filósofo Heidegger e o psiquiatra e psicanalista suíço Medard Boss mantiveram entre si uma correspondência que se inicia no apósguerra (1947) e um projeto de parceria intelectual que se concretizou nos já famosos Seminários de Zollikon. Os encontros são frutos do desejo do segundo de enxertar em sua prática clínica os geniais 'insight' de Heidegger e desse de ver sua filosofia sair do mundo acadêmico e "beneficiar um número muito maior de pessoas e, principalmente, pessoas necessitadas de ajuda" (HEIDEGGER, 2001, p. 11).

Os seminários, mantidos de 1959 a 1969, foram também uma maneira de Medard Boss socializar com 'amigos, colegas e alunos' da clínica de psiquiatria da Universidade de Zurique (Burghölzli) os freqüentes encontros que mantinha com o 'grande pensador'. No Prefácio à primeira edição, nos revela que "Entre os seminários sobravam a Martin Heidegger e a mim muitas horas para amplas conversas a dois" (HEIDEGGER, 2001, p. 14). Ao lado, portanto, do ensino 'exotérico' de Heidegger, há outro que poderíamos chamar de 'esotérico' reservado aos diálogos mais íntimos com Medard Boss por ocasião das visitas à sua casa em Zollikon e durante as férias em comum.

É precisamente e apenas o diálogo mantido numa dessas férias, em Taormina, o qual queremos registrar, analisar e comentar. A preferência se justifica se consideramos que, entre os 25 diálogos registrados nos Seminários de Zollikon, é o que de uma maneira mais específica e ampla aborda temas relacionados com a psicanálise.

\section{Os antecedentes da viagem}

Os prenúncios da viagem aparecem no post scriptum da carta de Heidegger ao 'caro amigo' datada de 3 de março de 1963: "Temos grandes planos para boas férias e descanso. Gostaríamos de viajar de avião até Taormina e Sicília por 14 dias, no fim de abril até o começo de maio, isto a partir de Zurique. O senhor não teria vontade"? (HEIDEGGER, 2001, p. 271).

Apenas cinco dias depois, a pergunta se torna uma demanda e uma sedução. A demanda aparece indiretamente na 'grande alegria', na 'tranqüilidade valiosa' e 'assistência' que a companhia do amigo médico

Revista de Filosofia, Curitiba, v. 17 n.20, p. 185-198, jan./jun. 2005. 
- que conhece a língua e a Itália - pode proporcionar ao casal Heidegger. A barganha irrecusável está clara no seguinte trecho da carta de 8.3.63:

Embora entre amigos não se devam fazer contas, quero dizerlhes que, por ocasião desta nova perspectiva inteiramente inesperada da possibilidade de viajar, seria para mim um prazer e ao mesmo tempo um auto-exame salutar cultivar um exercício fenomenológico a respeito de Ser e Tempo, diariamente com o senhor (HEIDEGGER, 2001, p.271).

Como resistir a uma proposta tão sedutora? Acertada a viagem, restava manter a promessa e, nesse sentido, escreve Heidegger no dia 1 de abril de 1963, sempre de Friburgo:

Como eu gostaria de realizar as conversas sobre textos de meus escritos, peço-lhe que me escreva quais os temas que o senhor deseja tratar. Escolherei, então, as páginas correspondentes, pois não poderíamos transportar uma biblioteca inteira para a Sicília [...] (HEIDEGGER, 2001, p.273).

No final da cartinha, uma afirmação que não deve passar despercebida: "Já estou vivendo inteiramente no mundo grego. Será agradável pensar na Grécia a partir da Sicília e achar que ambas são a mesma coisa" (Ibidem). Começam a se delinear, assim, alguns horizontes - que podemos distinguir, mas não separar - dentro dos quais se dão essas 'conversas sicilianas'. A metáfora do horizonte - como algo dentro do qual sempre nos situamos, mas sem jamais possuí-lo - foi escolhida para caracterizar esta tentativa de 'situar' as questões heideggerianas concernentes aos fundamentos conceituais científico-naturalistas da psicanálise.

\section{O horizonte geográfico-natural}

Há sem dúvida e antes de tudo o simples horizonte geográfico: as 'palmeira diante da janela', os 'passeios recreativos pelo jardim de San Domenico; o perambular pelas ruelas do lugar; os passeios no interior da ilha e, especialmente, a visão do mar, a ilha e seus habitantes que Heidegger contrapõe às macieiras e às pereiras em plena floração no seu retorno a Freiberg e que faziam parecer nova sua terra de origem (HEIDEGGER, 2001, p. 183; 275).

Por quanto interessante possa ser essa contraposição de uma geografia insular, marcada pelo mar, com aquela continental do sudeste

Revista de Filosofia, Curitiba, v. 17 n.20, p. 185-198, jan./jun. 2005. 
alemão, mais telúrica, não é ela que nos interessa porque o 'prazeroso' e 'salutar' 'auto-exame' em cultivar um 'exercício fenomenológico' a respeito de Ser eTempo não se dá numa natureza que lhe serviria apenas de moldura extema. Filosofia (metafísica) e Natureza estão profundamente imbricadas no pensamento heideggeriano. A Natureza, de fato, mesmo no seu sentido mais amplo e não apenas da física moderna, é um ente que só 'ingressa no mundo' quando algo lhe 'acontece'. É com a imupção de um ente que tem a característica de ser um ser-no-mundo (Dasein) que chega a hora e o dia da possibilidade do ente manifestar-se (HEIDEGGER, 1979, p. 116).

Nas conversas sicilianas, essa idéia está claramente expressa na seguinte afirmação: "Para que um ente possa estar presente e mesmo para que possa haver um ser, a condição de abertura do ser é necessário o estar do homem já no aí, na clareira, na claridade do ser, modo este como o homem existe. Não pode haver, pois, ser do ente sem o homem" (HEIDEGGER, 2001, p. 195). O 'relógio atômico' das substâncias radioativas atesta sem dúvida que a terra pode ser sem o homem, em outras palavras, que há 'presença' que não precisa do homem, todavia o é, já era, o ser permanece indeterminado. O Dasein é o 'pastor' da clareira.

Além desse horizonte 'da natureza' há um outro igualmente importante, o histórico: pensar a Grécia a partir da Sicília.

\section{O horizonte greco-histórico}

De fato, essa viagem de 1963 é a continuação daquela empreendida por Heidegger um ano antes de navio pelos lugares memoráveis da península e das ilhas gregas (HEIDEGGER, 2000; SAFRANSKI, 2000, p. 466-469; LOPARIC, 2004, p. 32-33). ${ }^{2}$ O fascínio do mundo grego está ligado ao fato de que "no começo da história ocidental as artes atingiram na Grécia os mais altos picos de sua exposição. Fizeram brilhar a presença dos deuses, os diálogos do destino humano e do divino" (HEIDEGGER apud SAFRANSKI, 2000, p. 466). Não é, porém, apenas esse 'primeiro começo' da história ocidental ou a simples e possível alienante 'lembrança' dos gregos que lhe interessava, mas também e especialmen-

2 Sobre essa primeira viagem à Grécia (HEIDEGGER, 2000), veja também alguns rápidos comentários em: SAFRANSKI (2000) e sobre a Grécia como uma das 'moradas de Heidegger' leia Loparic (2004).

Revista de Filosofia, Curitiba, v. 17 n.20, p. 185-198, jan./jun. 2005. 
te o confronto desafiador do mundo grego com o asiático, o que hoje exige do filósofo - para se manter fiel aos gregos - pensar e se confrontar com os desafios contemporâneos, como os da tecno-ciência (HEIDEGGER apud SAFRANSKI, 2000, p. 466-469).

Esse confronto Ocidente - Oriente se evidencia no final da conversa, quando Boss provoca Heidegger ao confrontar a concepção do Dasein - como 'guardião da clareira, do acontecimento' -com o pensamento hindu que não necessita de guardião da clareira porque 0 que há é apenas 'iluminação em e por si só' (HEIDEGGER, 2001, p. 196). Essa confrontação aponta, evidentemente, para o grande horizonte da ontologia.

\section{O horizonte do ser e do Dasein}

Com certa liberdade a respeito da já fragmentada fala de Heidegger registrada por Medard Boss, mas servindo-nos exclusivamente dela, apresento alguns traços que espero suficientes para delinear esse importante horizonte.

Parto de uma pergunta de Boss querendo saber o que significa realmente a frase central e recorrente, em Ser e Tempo, mesmo com alguma pequena variação: 'Dasein é aquele ente para cujo ser trata-se de si mesmo' (HEIDEGGER, 2001, p. 182).

Heidegger (1979, p. 115) já tinha explicitado, em Sobre a essência do fundamento, que a proposição O ser-aí existe em-vista-de-si-mesmo não deve ser entendida como uma afirmação de um solipsismo narcísico e egoístico do Dasein, mas como condição de possibilidade para que o homem se comporte egoística ou altruisticamente. Trata-se de uma proposição de uma analítica ontológica e não ôntica do Dasein.

Nesta conversa em Sicília, reaparece claramente que a questão de fundo, o interesse, projeto filosófico ou destino que Heidegger persegue não é propriamente o antropológico, mas o ontológico. Ė a questão do ser em geral que para ser entendida parte daquele ente que se coloca essa questão. A existência, a vida humana, o Dasein é antes de tudo compreensão de ser. Segundo suas próprias palavras, "a referência à compreensão-do-ser aponta para a determinação 'mais profunda' da essência do ser humano" (HEIDEGGER, 2001, p. 177). É essa compreensão que fundamenta sua relação com os entes, ocupando-se das coisas ou

Revista de Filosofia, Curitiba, v. 17 n.20, p. 185-198, jan./jun. 2005. 
cuidando dos outros. O dasein é um ser-no-mundo, um ser situado na 'clareira do ser' (HEIDEGGER, 2001, p. 182). Os traços originários, cooriginários, 'equi-primordiais' os existenciais do Dasein que integram sua estrutura fundamental são o ser-em, compreender, preocupação, serno-mundo. Nas palavras de Heidegger nessas conversas sicilianas. "O ser do Dasein significa: já ser adiante-de-si-em (no mundo) como estarjunto a (entes que vem ao encontro dentro do mundo)" (HEIDEGGER, 2001, p.193).

Nesse sentido, o 'se' de relacionar-se e 'meu' do meu Dasein não devem ser compreendidos como referente a um sujeito ou substância (HEIDEGGER, 2001, p. 182; 183). Essa analítica da existência permite a Heidegger renunciar à metafísica da subjetividade para dar conta fenomenologicamente da vida humana e ao mesmo tempo se opor tenazmente a todas as tentativas de reduzir o homem a um 'objeto' visto que o que o define é o poder-ser. Descortina-se, assim, o outro horizonte da crítica à ciência e à técnica dentro do qual se movimentará especialmente a reflexão posterior do filósofo alemão.

\section{O horizonte da ciência e da técnica}

A relação do homem com a ciência e a técnica foi das mais explorada em Zollikon, talvez em virtude de um público que julgasse ou desejasse assentar sua prática médica, psiquiátrica, psicológica ou psicanalítica no terreno de uma objetividade científica.

Não é nossa intenção percorrer "os caminhos" de Heidegger sobre esse tema, partindo da ontologia da facticidade, passando pela analítica existencial, a identificação dos perigos da técnica, as tentativas e o malogro de uma superação individual ou coletiva da crise. Aqui, basta-nos relembrar o traçado básico, percorrido com perseverança até o fim pelo filósofo, no sentido de apresentar seu pensar como uma tentativa de responder à pergunta pelo sentido do ser o que implicava a desobjetificação de todo ente, a começar pelo Dasein. Esse projeto implicava a desconstrução tanto da metafísica quanto da ciência e técnica modernas entendidas como encobridoras do fenômeno originário do ser. Mesmo que agora a superação da crise da técnica não esteja no poder do Dasein individual ou coletivo, porque ela é um 'destinamento', 'acontecimento' do ser, é preciso preparar-se e esperar por um novo

Revista de Filosofia, Curitiba, v. 17 n.20, p. 185-198, jan./jun. 2005. 
horizonte quando o ser no seu todo se manifestará numa outra verdade, num novo modo de presença, não mais coisificado.

Nestas conversas sicilianas, Heidegger retoma essas idéias e manifesta suas reservas com relação a uma determinada concepção de ciência que ele situa no começo da modernidade. Um conceito e projeto que exclui as qualidades e somente enxerga quantidades mensuráveis, pontos de massa em suas conexões espaço temporais, possibilitando dessa maneira o controle e a previsibilidade (HEIDEGGER, 2001, p.177). Enquanto a ciência galileiana só trabalha com o movimento entendido como mudança de lugar no tempo, os gregos conheciam quatro tipos de movimento, diligentemente anotados em grego por M. Boss: genesis (gênese) - phthorá (desaparecimento); auxesis (crescimento) - phthisis (decadência); alloiosis (transformação); phorá (transporte de um lugar a outro) e, finalmente, o nome grego para o fundamento, a definição formal de todo movimento que é a metabolé, a transformação de algo em algo diferente (HEIDEGGER, 2001, p. 179-180).

\section{Críticas às ciências humanas em geral}

Antes de analisar as críticas específicas dirigidas à psicanálise freudiana, é preciso reconhecer que elas se situam no espectro mais amplo das 'ciências humanas'. Fundamentalmente, dizem respeito ao método objetivante de análise do fenômeno humano o que leva ao reducionismo explicativo, seja ele de natureza físico-químico ou cultural.

É denunciado, antes de tudo, o método inadequado utilizado pela ciência moderna para captar a 'humanitas' do homem, isso é a "relação livre do ser humano com aquilo que o encontra, o apropriar-se destas relações e deixar-se solicitar por elas" resultando no que poderíamos chamar de reducionismo explicativo do Dasein (HEIDEGGER, 2001, p. 178). Em outras palavras, a metodologia empregada pela Psicologia, Antropologia, Psicopatologia não consegue dar conta do homem enquanto homem, mas o estuda como um simples objeto, um ente entre outros, pertencente ao conjunto dos entes que podem ser objeto de 'verificação empírica' (HEIDEGGER, 2001, p. 176-177).

O Dasein, porém, não é um objeto. O que o caracteriza é sua abertura, clareira. A 'essência' do Dasein é justamente o seu poder-ser, não no sentido de um ser que atualizaria suas possibilidades, como o tronco de

Revista de Filosofia, Curitiba, v. 17 n.20, p. 185-198, jan./jun. 2005. 
árvore poder ser uma viga de madeira (HEIDEGGER, 2001, p. 186). "As possibilidades do Dasein - escreve Heidegger - não são tendências ou capacidades em um sujeito. Elas sempre resultam primeiro, a bem dizer, a partir de 'fora' de cada situação histórica do poder-se relacionar e escolher, da relação com o que vem ao encontro." (HEIDEGGER, 2001, p. 181)

Nesse sentido, o método utilizado por essas ciências comportamentais "que manipulam o homem por controle remoto pertencem ao conceito de natureza de Galilei e Newton" de que se falou anteriormente (HEIDEGGER, 2001, p. 177).

A ciência situa a explicação do fenômeno da relação com o outro como algo da ordem do fisiológico. Segundo Heidegger, porém, se o fisiológico é uma condição necessária para a possibilidade de uma relação humana com o outro, não é uma condição suficiente. É uma conclusão errada confundir condição necessária com 'causa originária' e 'fundamento'. Com certa ironia, arremata seu pensamento: "Se o fisiológico fosse o fundamento do humano deveria haver, por exemplo 'moléculas de despedida'” (HEIDEGGER, 2001, p. 179).

"O corporal do homem nunca pode, fundamentalmente nunca, ser considerado como algo apenas simplesmente presente, se quisermos observá-lo adequadamente. Se eu colocar o corporal do homem como algo simplesmente presente já o destruí a priori como corpo" (HEIDEGGER, 2001, p.190).

Igualmente equivocada é a explicação culturalista. Nesse sentido, é interessante notar que o filósofo não desconhece alguns desdobramentos da psicanálise, tais como a corrente culturalista. Logo de início, ao citar Sullivan, um de seus representantes mais significativos ao lado de Karen Horney e Erich Fromm, critica a concepção de homem como um ente que é determinado pela relação com outros homens. Concorda que nesse caso possa se falar de uma 'característica', mas não de uma 'constituição', de uma determinação exaustiva do ser humano, visto que a 'essência mais profunda do ser humano' é sua referência à compreensão-do-ser (HEIDEGGER, 2001, p. 176-177).

\section{As críticas à psicanálise}

Nas conversas sicilianas, Heidegger tangencia vários temas psicanalíticos - representação (184), introjeção (185), projeção (185), trans- 
ferência (186), afeto (187), terapia (188), memória-esquecimento (consciente-inconsciente) (188-190), pulsão e libido (191-193), recalque (190), instâncias psíquicas: id, ego, superego (194) - e os confronta com sua analítica do Dasein. Na tentativa de organizar as várias críticas que se sucedem sem uma aparente ordem lógica na apressada estenografia do atento e interessado interlocutor, as articularemos a partir da definição que o próprio Freud nos deu de sua criatura: a psicanálise é um método de investigação do inconsciente, uma terapêutica, uma metapsicologia (FREUD, 1987a, p. 287).

\section{O método investigativo da psicanálise freudiana}

O que Heidegger parece insinuar, nas breves alusões que se encontram no registro destas conversas sicilianas sobre esse tópico, é que o método da psicanálise continua devedor daquele da ciência moderna a despeito de seu discurso parecer se deslocar do físico para o psíquico. É por isso que - na compreensão do filósofo - Freud não consegue nos dar verdadeiramente uma 'história' da vida psíquica, mas apenas "uma cadeia causal-naturalista, uma cadeia de causa e efeito e, ainda por cima, uma cadeia construída" (HEIDEGGER, 2001, p. 181). Explicar o homem a partir das pulsões é adotar um método científico inadequado por considerar o homem como uma máquina. "Por isso afirma Heidegger - é fundamentalmente discutível se um método tão determinado por uma objetividade não-humana pode mesmo ser apropriado para afirmar o que quer que seja sobre o homem qua homem" (HEIDEGGER, 2001, p. 192).

À explicação causal dos fenômenos humanos, Heidegger contrapõe uma compreensão fenomenológica. O diálogo, por exemplo, que está se travando entre ele e M. Boss não deve ser explicado a partir de uma 'causa', um desejo', um 'mecanismo de pulsão mitológico', mas compreendido como algo determinado "pela tarefa que tenho diante de mim. Isto é o motivo, 0 'porquê' [...] algo que está à minha frente, uma tarefa na qual eu estou empenhado, algo de que eu sou encamegado" (HEIDEGGER, 2001, p. 192-193).

Em suma, a psicanálise vê do Dasein somente sua modificação da queda em e para dentro do desejo. Ao colocar, porém, o desejo e a 'impulsividade' como o propriamente humano, o torna um mero objeto (HEIDEGGER, 2001, p. 193).

Revista de Filosofia, Curitiba, v. 17 n.20, p. 185-198, jan./jun. 2005. 
A terapia

Nas conversas sicilianas, Heidegger não toca tematicamente 0 tema da técnica e dos objetivos terapêuticos da psicanálise. Existem, porém, algumas alusões interessantes com relação à necessidade de ajuda do ser humano, aos objetivos da terapia em geral e duas perguntas específicas de Boss com relação à sexualidade.

A necessidade de ajuda decorre do fato que o homem, por ser livre, está sempre em perigo de se perder, de não saber lidar adequadamente consigo mesmo e por ser essencialmente imperfeito, 'pode-serdoente' (HEIDEGGER, 2001, p. 180).

Nesse sentido, a terapia deve ser exercida "para ajudar as pessoas, para que elas alcancem a adaptação e a liberdade no sentido mais amplo. Isto diz respeito tanto a médicos como a sociólogos, pois todas as perturbações sociológicas e de saúde do indivíduo são perturbações da adaptação e da liberdade" (HEIDEGGER, 2001, p. 178).

Tendo presente esses objetivos, é mais fácil entender a resposta que Heidegger dá à pergunta de $\mathrm{M}$. Boss: "O que significa do ponto de vista terapêutico minha pergunta: 'Por que o ente masculino só pode encontrá-la sempre como algo perigoso?' (HEIDEGGER, 2001, p. 188). Através de tais perguntas - responde o filósofo - abre-se olhar da mulher, muda-se a 'afinação' dela para o ente masculino e dessa maneira pode se tornar mais livre com relação ao ser-masculino. "O ser-livre para algo é por si só uma afinação solta e prazerosa” (HEIDEGGER, 2001, p.188).

Já quanto à segunda pergunta relativa à dificuldade encontrada por psicólogo e pelo próprio Freud, de determinar a essência da masculinidade e da feminilidade, a resposta do filósofo é enigmática: "por causa da cegueira essencial inata do ser humano" (HEIDEGGER, 2001, p.188).

Em Os Seminários de Zollikon, a posição de Heidegger com relação à terapia psicanalítica é até positiva. ${ }^{3}$ Suas críticas mais duras se dirigem à fundamentação teórica.

3 “E o estranho é que isto realmente funciona”. (HEIDEGGER, 2001, p. 48) 
A teoria

Mesmo nos servindo apenas da pequena amostra dessas conversas sicilianas é possível inferir que Heidegger conhece o essencial da metapsicologia freudiana: primeira e segunda tópica, teoria da libido etc. A crítica aparece na forma de uma pergunta que é mais de natureza retórica do que realmente dubitativa: "será que em toda a construção freudiana da teoria da libido o homem está mesmo aí?' (HEIDEGGER, 2001, p. 192).

Evidentemente, sua resposta de Heidegger é negativa porque a teoria psicanalítica é o reflexo do conceito de teoria no sentido moderno, isso é, "uma suposição construtiva para o fim de uma ordenação irrefutável de um fato em um contexto mais amplo, no contexto já existente de natureza no sentido newtoniano" (HEIDEGGER, 2001, p. 177).

Em outras palavras, a psicanálise 'explica' a partir de 'causas' e não 'compreende' a partir de 'motivos'. Recorrer a explicações intrapsíquicas de fenômenos como a representação, o fantasiar, a percepção do outro, os afetos, o esquecimento, o querer, o desejar, apelando a conceitos de pulsão, introjeção, projeção, transferência, recalque, consciente, inconsciente é ainda permanecer dentro de uma metafísica da subjetividade, mesmo que de um sujeito objetivado - e de uma concepção naturalista, causal e determinista de natureza. "Todo começar no intra-psíquico e a partir da consciência - afirma Heidegger - é abstrato, uma construção não identificável. As relações de mundo circundante de um objeto não precisam de explicação, elas só precisam ser vistas" (HEIDEGGER, 2001, p.184).

Explicar a teoria da representação mental a partir de estímulos sensoriais é 'pura mistificação', "pura invenção, construções a partir de uma posição calculista, teórico-causal, explicativa em face do ente" (HEIDEGGER, 2001, p.184). Explicar a percepção do outro a partir de conceitos de empatia e projeção 'não significa nada'. A introjeção de que fala o mundo 'psi' é o contrário do que se dá fenomenologicamente. A projeção de nosso lado mau no outro, que por causa disso passa a ser odiado, 'não precisa ser uma projeção, nem pode ser projeção' e assim por diante.

Em suma, ao se falar de atos psíquicos, "a psique é pensada como um âmbito interior existente por si. Entretanto, a partir de tais psiquismos nunca se chega à estrutura-de-cuidado, ao ser-no- mundo" (HEIDEGGER, 2001, p. 191).

Revista de Filosofia, Curitiba, v. 17 n.20, p. 185-198, jan./jun. 2005. 
À explicação causalista da psicanálise, Heidegger contrapõe uma descrição fenomenológica. Dessa maneira, vai desconstruindo os conceitos-chaves da metapsicologia freudiana, mostrando que podem ser reconduzidos a traços essenciais e modos mais originários do ser do Dasein: o ser-com o outro e do outro comigo (percepção do outro, 184); o ser-no-mundo (introjeção, 185); o poder-ser (projeção, 185); afinação (transferência, 186-187); a diferença entre reter, recordar, esquecer (desejo inconsciente, recalque, 189-190)

O que dizer dessa contraposição frontal entre analítica do Dasein e psicanálise? Como Freud responderia essas críticas?

\section{Considerações finais}

Foge aos limites de tempo e de espaço uma confrontação mais exaustiva e interessante do que poderíamos chamar de tópicas freudianas e heideggerianas do ser humano. É inegável que, ao lado de inúmeras aproximações que é possível estabelecer entre essas duas grandes e ousadas construções teóricas devemos constatar uma série de jogos de linguagem, constelações semânticas que apontam para divergências substanciais (LOPARIC, 1990, p. 225-245).

Difícil ou impossível saber o que Freud responderia às críticas de Heidegger se tivesse acesso a elas. Todavia, algo equivalente aconteceu com o Professor de filosofia Werner Achelis, que lhe submeteu para apreciação um ensaio filosófico sobre A interpretação dos sonhos antes de sua publicação, em 1927.

Freud agradece o gesto, 'a polidez rara entre os estudiosos alemães', mas responde com certa impaciência e rudez diante de alguns equívocos grosseiros do autor e aproveita para dizer com toda clareza 0 que ele pensa da filosofia (metafísica).

Outros defeitos da minha natureza sem dúvida me entristeceram e me fizeram sentir-me humilde; com a metafísica é diferente: não só não tenho nenhum talento, mas tampouco nenhum respeito por ela. Em segredo - não se pode dizer essas coisas em voz alta - creio que um dia a metafísica será condenada como uma praga, como um mau uso do pensamento, como uma sobrevivência do período da Weltanschauung religiosa. Bem sei até que ponto este modo de pensar me

Revista de Filosofia, Curitiba, v. 17 n.20, p. 185-198, jan./jun. 2005. 
aliena da vida cultural alemã. [...] Como quer que seja, certamente é mais simples orientar-se alguém "neste mudo" de fatos do que no "outro mundo" da filosofia (Carta a Werner Achelis de 30.01.1927. FREUD, 1982, p. 432).

Com tanta 'clareira', 'cegueira' e 'surdez' parece impossível fazer dialogar entre si os dois grandes pensadores de língua alemã e de alguma maneira também nossos pais simbólicos por nos situarmos nessa área de fronteira entre filosofia e psicanálise.

Penso que não devemos lamentar as divergências e que não somos obrigados a aderir incondicionalmente a uma ou outra dessas duas gigantescas tentativas de lançar alguma luz sobre o humano. Entre assumir a provocação, defendendo, numa postura apologética, um ou outro dos dois discursos ou cair na tentação de um ecletismo apaziguador resta sempre a possibilidade de tentar compreender, num esforço hermenêutico, as razões de cada um.

Melhor ainda se a linguagem nova por eles encontrada - para não colocar vinho novo em odres velhos - não sirva apenas para enriquecer nosso acervo de fórmulas, mas nos force a pensar e nos sirva de estímulo e exemplo para encontrarmos outros jogos de linguagem na tentativa, sempre precária, de explicar mais com Freud para compreender melhor com Heidegger.

\section{Referências}

FREUD, S. Correspondência de amor e outras cartas, 1873-1939. Rio de Janeiro, RJ: Nova Fronteira, 1982.

. Dois verbetes de enciclopédia. In: Edição standart brasileira das obras psicológicas completas. 2. ed. Rio de Janeiro,RJ: Imago, 1987a. v. 18. Publicado originalmente em 1923.

FREUD, S. Kell-e Az Egyetemen: A psychoanalyst Tanitani?. In: Edição standart brasileira das obras psicológicas completas. 2. ed. Rio de Janeiro,RJ: Imago, 1987b. v. 17. Publicado originalmente em 1919.

HEIDEGGER, M. Os seminários de Zollikon. São Paulo, SP: EDUC, 2001.

Revista de Filosofia, Curitiba, v. 17 n.20, p. 185-198, jan./jun. 2005. 
. Sobre a essência do fundamento: Conferências e escritos filosóficos. São Paulo, SP: Abril Cultural, 1979.

. Soggiorni: viaggio in Grecia. Milano: Guanda, 2000.

LOPARIC, Zeljko. Heidegger. Rio de Janeiro, RJ: Jorge Zahar, 2004.

. Heidegger, réu: um ensaio sobre a periculosidade da filosofia. Campinas, SP: Papirus, 1990.

SAFRANSKI, Rüdiger. Heidegger, um mestre da Alemanha entre o bem e o mal. São Paulo, SP: Geração, 2000.

Recebido em: Received in: 02/12/ 2004 Aprovado em: Approved in: 13/02/2005 